Scientiæ Studia, São Paulo, v. 12, n. 2, p. 379-88, 2014

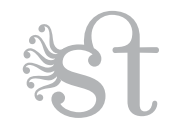

\title{
Valsa para carrapatos
}

Lorenzo Baravalle

\author{
A foray into the worlds of animals and humans/A theory of meaning \\ Jakob von Uexküll \\ Translation: J. D. O'Neil \\ University of Minnesota Press \\ Minneapolis/London, 2010, 272 págs.
}

Los ojos en que te miras

son ojos porque te ven.

Antonio Machado. Proverbios y cantares, XL.

Um carrapato faminto aguarda paciente, na ponta de um galho, a passagem de sua presa. De repente, a espessa escuridão dessa espera sem eventos quebra-se. Os órgãos receptores do carrapato enchem-se do aroma do ácido butanoico. Suas pequenas pernas abrem-se, e o inseto deixa-se cair entre os pelos de um mamífero. O impacto desperta o carrapato como de um sono. A pele macia e quente de sua vítima é o sinal que chegou a hora de comer.

Com essas imagens começa a incursão de Jakob von Uexküll (1864-1944), brilhante biólogo e precursor da etologia contemporânea, nos mundos (ou, usando a terminologia do autor, nos Umwelten, isto é, os ambientes vitais, os mundos fenomênicos) dos animais e dos humanos. O quesito que acompanha o autor ao longo de sua viagem é o seguinte: pode o carrapato ser uma máquina sem condutor? Em outras palavras, será que ele é apenas um autômato programado para sobreviver? É, para Uexküll, até demasiado evidente que a resposta a essas perguntas é não. Nem a fisiologia behaviorista nem a teoria da seleção natural, com suas ferramentas conceituais fundamentalmente mecanicistas, conseguem explicar a complexidade das respostas comportamentais de um organismo. Para entender porque o carrapato, assim como qualquer outro animal e obviamente também os seres humanos, agem como agem, é preciso explorar o universo de sua interioridade, aquele espaço onde o entremeado das percepções desvela significados ocultos. Esse universo, que o filósofo Gilbert Ryle consideraria povoado apenas por fantasmas, aparece logo cheio de vida nas páginas de Uexküll, inspiradas por um declarado idealismo filosófico. 
A nova tradução ao inglês das duas obras clássicas do cientista alemão - que, na verdade, nasceu na atual Estônia -, A foray into the worlds of animals and humans e A theory of meaning, chega talvez tarde mas, ao mesmo tempo, em felizes circunstâncias. Tarde, tendo em conta que as edições originais datam, respetivamente, de 1934 e 194,o, e que a primeira tradução do primeiro texto, de 1957, é considerada, pelo tradutor da nova edição, pouco fiel ao cuidado terminológico do autor (cf. O'Neil, 2010). Em felizes circunstâncias, porque hoje, mais do que no passado, o trabalho de Uexküll está na condição de receber o merecido reconhecimento. Seu principal objetivo polêmico era, como já antecipei, a fisiologia behaviorista - cuja figura principal era Jacques Loeb, professor de John B. Watson - predominante na época, em particular nos Estados Unidos, que ao longo do século xx inspirará boa parte da biologia e da psicologia do comportamento (pense-se, por exemplo, nos programas de pesquisa da sociobiologia e da ecologia comportamental). Aliás, Uexküll, embora não explicitamente antidarwinista, não parecia simpatizar com a teoria da seleção natural. Em uma época de grande fervor em torno da nascente síntese moderna da biologia é, portanto, fácil entender por que o trabalho do fisiólogo ultrapassou com dificuldade as fronteiras dos países de língua alemã. Nestes últimos, contudo, a influência dele foi constante e decisiva. Encontramos referências a Uexküll no âmbito da literatura filosófica, por exemplo, em Cassirer (1979, v. 4, p. 242-50) e em Heidegger - a noção de Dasein heideggeriana é reconhecidamente devedora dos Umwelten uexküllianos (cf. Heidegger, 1995, p. 261-7; Agamben, 2006, cap. 10) - e, em âmbito científico, seus trabalhos foram fundamentais na formação de Konrad Lorenz (1974; cf. Baravalle, neste número). Na atualidade, o crescente interesse pelo papel da informação nos processos biológicos tanto moleculares como comportamentais (cf. Godfrey-Smith \& Sterelny, 2008; Emmeche \& Kull, 2011), em detrimento dos enfoques behavioristas, assim como o questionamento da abrangência do darwinismo e a aceitação da relevância de mecanismos evolutivos alternativos, por exemplo, lamarckianos (cf. Jablonka \& Lamb, 2005), são, com certeza, sinais de que chegou o tempo para tentar uma releitura do legado de Uexküll.

Entre $A$ foray into the worlds of animals and humans e $A$ theory of meaning existe uma certa sobreposição de conteúdo. Ambas as obras estudam os fenômenos semióticos no mundo natural e no comportamento animal, a partir da teoria do ciclo funcional. A foray into the worlds of animals and humans deve muito de seu interesse à beleza das descrições e das sugestivas imagens da experiência subjetiva de diversos animais. Não sendo possível reproduzir aqui as características próprias de cada um deles, limitarme-ei a fazer referência a alguns exemplos ao longo da resenha, usando o caso do carrapato como paradigmático e seguindo nisso Agamben (2006, cap. 11). Na seção 1, resumirei os principais resultados teóricos alcançados pelo autor nessa obra, tentando refletir uma ordem conceitual ideal. Entretanto, A theory of meaning é uma obra mais 
especulativa, que tem em vista oferecer uma visão de conjunto sobre o universo das relações simbólicas. Ela é rica de sugestões filosóficas, nem sempre apresentadas claramente ou discutidas apropriadamente. A seção 2, será portanto dedicada, na medida do possível, a uma exposição dos elementos mais inovadores no pensamento do autor, de maneira a facilitar a tarefa do leitor que queira se aproximar dele.

\section{Giclos funcionais e Umwelten: os mundos dos animais e dos humanos}

De modo a poder avaliar ponderadamente a contribuição de Uexküll para o debate filosófico-científico atual, é fundamental compreender o papel que jogam alguns conceitos-chave em sua interpretação dos processos vitais. Antes que tudo, é importante assinalar a insatisfação do biólogo com as explicações mecanicistas causais em fisiologia. Estas tinham como padrão, na época, o modelo do arco reflexo. No caso do carrapato,

as células sensoriais, que ativam a estimulação sensorial, e as células motrizes, que ativam o impulso ao movimento, são conetores que transmitem uma onda de excitação puramente física, produzida pelo receptor nervoso em resposta ao impulso externo. O inteiro arco reflexo funciona por uma transferência de movimento, exatamente como qualquer máquina. Não há evidências da presença de fatores subjetivos em lugar algum (Uexküll, 2010, p. 46, grifo meu).

A esse esquema explicativo, considerado superficial e incompleto em vários trechos de suas obras (cf. p. 46-7, 161-3), Uexküll opõe o já citado modelo do ciclo funcional. A relevância deste último na economia do pensamento do autor é tão grande, que seria possível dizer que o objetivo principal de ambos os escritos aqui discutidos é oferecer sua justificação teórica e estabelecer seu alcance. É, de fato, a partir da plausibilidade científica de tal modelo que Uexküll consegue justificar e articular a noção de Umwelt (traduzido na edição aqui resenhada simplesmente como "mundo" (world), a qual define o horizonte fenomênico, vivencial e simbólico do animal.

Qualquer ciclo funcional de estímulo e resposta é constituído por dois elementos: um sujeito e um objeto. Ambos possuem uma certa estrutura física, porém a interação entre eles não é propriamente física, mas depende de um processo que poderíamos chamar de informacional ou semiótico. O objeto constitui, para o sujeito, um sinal de percepção que ativa conjuntos de células, coordenadas por um "órgão de percepção", geralmente o cérebro - para tipos distintos mais primitivos de coordenação perceptiva (cf. p. $7^{3-8)}$, nas plantas (cf. p. 150-1). O processamento interno de tal sinal, que é representado como um problema ambiental para o organismo, gera uma resposta 
comportamental. Esta é, por sua vez, veiculada por outras características do objeto, que constituem, de acordo com a terminologia de Uexküll, o sinal de efeito. A figura 1 ilustra a concatenação de sinais no ciclo funcional:

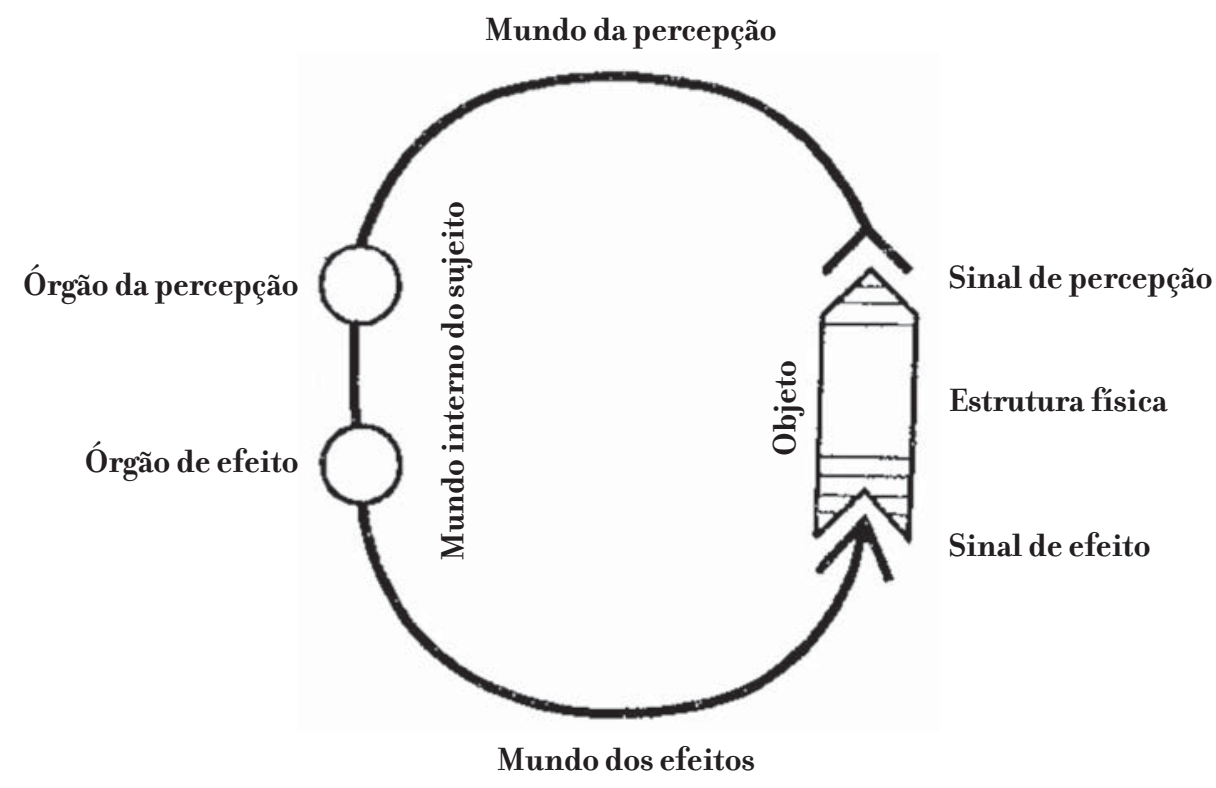

Figura 1. O ciclo funcional. O objeto físico, à direita na imagem, é a fonte de informação simbólica captada pelos órgãos perceptivos do animal. Durante a primeira parte do ciclo, correspondente à cauda da seta, o objeto passa a fazer parte do mundo sensível do sujeito, à esquerda da imagem. Isso produz uma estimulação dos órgãos de efeito que desencadeia, por meio de alguma representação no mundo interior do animal, a busca de uma informação ambiental para realizar a ação adequada. Finalmente, o ciclo funcional fecha-se quando o sujeito encontra no objeto o sinal do efeito que estava procurando e torna-se, assim, causa de um evento físico (cf. Uexküll, 2010, p. 49).

A coordenação entre percepção e efeito comportamental não pode ser mecânica nem cega, como acreditam os behavioristas, já que é preciso que nela se dê uma correta interpretação dos sinais produzidos pelo objeto, processo que, é fácil observar na natureza, nem sempre é realizado corretamente. Com relação a isso, Uexküll cita uma série de experimentos dirigidos a dissociar sinais de percepção e sinais de efeito: sobre a chamada de acasalamento nos gafanhotos (cf. p. 88); sobre a recepção dos pedidos de ajuda dos pintinhos à mãe galinha (cf. p. 90-1); sobre o fenômeno do imprinting (cf. 108-13). Tampouco o objeto pode ser simplesmente entendido como objeto físico, já que no ciclo funcional ele não produz certas percepções ou estímulos efetivos apenas em virtude de sua estrutura material e causal, mas também e sobretudo, graças a certas propriedades simbólicas que derivam de sua interação com o sujeito. É relativa- 
mente fácil identificar aqui a influência da epistemologia kantiana na teoria de Uexküll. O objeto é principalmente objeto fenomênico, dado funcionalmente ao sujeito conforme suas faculdades perceptivas e efetivas.

No caso do carrapato, o objeto percebido constitui-se a partir do aroma do ácido butanoico. As características que nós humanos consideramos próprias dos mamíferos, assim como as distinções que podemos fazer entre vários deles, são inteiramente desconhecidas para o carrapato. Contudo, ele consegue identificar infalivelmente um mamífero e distingui-lo de qualquer outro animal que não pertença a essa classe, já que nenhum outro animal pode ativar seus receptores (p. 179). Só quando a percepção do ácido butanoico é adequadamente processada o carrapato deixa-se cair entre os pelos da vítima. Aqui ativam-se sinais de efeito de intensidade variada, correspondentes à temperatura e às características da pele do mamífero, que dirigem o carrapato em direção à área melhor para começar a sução de sangue. Esse processo é descrito, com alguma diferença, tanto em $A$ foray into the worlds of animals and humans (p. 44, 52) como em $A$ theory of meaning (p. 178-9). Em ambos os textos, Uexküll mostra-se consciente de que um adversário behaviorista poderia questionar esse conhecimento do mundo interior do carrapato. A estratégia de defesa de suas teses é parcialmente diferente nas duas obras. EmA theory of meaning (p. 159), Uexküll invoca as célebres considerações sobre as duas mesas, a física e a fenomênica, de Eddington. O behaviorista, segundo o autor, é ingenuamente antimetafísico por acreditar que toda a realidade é dada em uma teoria física, ou está baseada nela. A observação "ingênua” de como nós e os outros, humanos e animais, interagimos com as coisas deve ser considerada uma evidência, também científica, de que o comportamento não se reduz a mero mecanismo. Em A foray into the worlds of animals and humans, essa tese é apoiada por um grande número de experimentos e experiências diretas.

O mundo interior do sujeito, onde o sinal perceptivo é elaborado e uma determinada classe de efeitos são estimulados, é chamado por Uexküll, como já antecipamos, de Umwelt. O Umwelt é o lugar onde os sinais do mundo exterior se configuram de acordo com uma modalidade fenomênica particular, diferente de animal a animal. Ele é o núcleo do ciclo funcional. Para tentar descrever os distintos Umwelten, Uexküll recorre a metáforas baseadas nas cores ou na música (esta última analogia revelará ter um alcance bem mais amplo ao longo de $A$ theory of meaning). Dados os distintos aparatos perceptivos e as distintas morfologias das espécies animais, os objetos mostramse nos respetivos Umwelten com distintas tonalidades, de acordo com as quais os organismos podem interagir com o ambiente. Um Umwelt manifesta-se primariamente como uma dimensão espaço-temporal (p. $5^{3-7_{2}}$ ) na qual apenas os objetos funcionalmente disponíveis aparecem ao animal, conforme suas atitudes perceptivas e efetivas. $\mathrm{O}$ espaço resulta segmentado de maneira proporcional às necessidades perceptivas do 
animal - isto é, com um detalhe não superior ao que o ciclo funcional requer para ser ativado - e estende-se conforme os objetos de interesse para o organismo - predadores, comida, refúgio etc. - apresentam-se nele. O espaço característico do Umwelt do carrapato é constituído apenas pela presença ou ausência da tonalidade correspondente ao ácido butanoico. Já a mosca, cuja percepção espacial é atentamente comparada por Uexküll com a nossa (p. 61-9), exibe um comportamento que evidencia a capacidade de localizar várias dimensões de movimento de acordo com a luminosidade. Também o tempo parece influir sobre a capacidade de individuar objetos funcionalmente significativos, como mostram experimentos sobre os diferentes tempos de reação de Betta splendens (o peixe de briga siamês) e dos caracóis comuns (p. 70-2).

Uma vez dadas as coordenadas espaço-temporais, os Umwelten distinguem-se por muitos outros fatores específicos, tais como (1) a arquitetura interna da percepção, seja como soma de estímulos, por exemplo, nas águas vivas ou no ouriço-do-mar

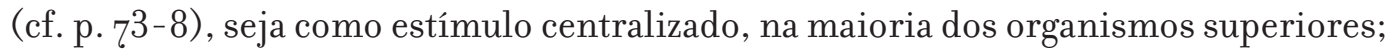
(2) o número de tipos de objetos que podem ser considerados como funcionalmente significantes (p. 79-84) e, em particular, (3) a capacidade de representar para si mesmo a interação com o objeto em termos de objetivos e fins (p. 86-92). Esta última não é exclusiva do Umwelt humano, mas, como é mostrado através de uma serie de observações sobre abelhas (p. 84, 180), paguros (p. 93) e cães (p. 93-q), parece estar presente em muitos animais. Obviamente não devemos pensar essa representação em termos conceituais. Ela corresponde, mais concretamente, à capacidade de transformar os sinais de percepção e de efeito em imagens, presentes quando o objeto está ausente (p. 92-8). A abelha que procura a colmeia, o paguro que escolhe sua concha e o cão que obedece às ordens do dono vivem uma situação de, diríamos hoje, soluções de problemas (problem solving), na qual tentam fazer coincidir uma representação, em forma de imagem, com o estímulo real (p. 113-q). A faculdade de representar para si mesmo imagens perceptivas e efetivas abre, para os organismos que a possuem, a possibilidade de ampliar extraordinariamente a extensão do próprio Umwelt. As tonalidades nas quais os objetos se apresentam ao animal tornam-se muito mais variadas, e um mesmo objeto pode estimular diferentes ciclos funcionais.

O Umwelt de boa parte das aves e de quase todos os mamíferos (mas também de alguns insetos) inclui, finalmente, a presença dos companheiros. Os outros animais passam a fazer parte do mundo subjetivo do organismo como possibilidades de percepção e de ação distintas daquela representada pelos objetos inanimados. Dessa maneira, a rede de intersignificação entre os vários habitantes de um certo ambiente ou ecossistema intensifica-se até formar um complexo de relações simbólicas que acaba reinterpretando o ambiente mesmo. Uexküll, a esse propósito, cita o exemplo do carvalho (p. 126-132), que constitui um ambiente compartilhado por um guarda-florestal, 
uma menina, uma raposa, uma coruja e diversos insetos. O carvalho físico quase desaparece, ocultado pelos inúmeros significados particulares que lhe são atribuídos por cada um dos organismos que interagem com ele.

\section{O MUNDO EM UMA GAIXA DE MÚSICA}

Se, por um lado, o mecanicismo dos fisiólogos behavioristas, com sua estrita noção de causalidade, não satisfaz Uexküll, por outro lado, como aparece mais claramente em A theory of meaning, também a explicação darwinista das adaptações parece-lhe inadequada. Embora Darwin seja citado apenas uma vez em $A$ foray into the worlds of animals and humans (p. 82), a propósito de um estudo sobre o comportamento das minhocas, é evidente a insatisfação de Uexküll com relação a uma teoria que vê na evolução o fator constitutivo da biodiversidade. Partindo de seus estudos sobre os animais, ele propõe então uma imagem alternativa da vida, baseada na noção de significado. Nessa concepção, a função de um órgão ou de um comportamento é considerada, em certa medida, anterior a sua estrutura, e o conjunto das relações físico-causais é subordinado às regras semânticas que governam as interações entre os organismos.

Diferentemente de um objeto inorgânico, como um sino cujas interações com o exterior estão limitadas a solicitações puramente mecânicas, nós seres orgânicos somos como uma coleção de sinos vivos,

cada um dos quais produz um tom diferente. Podemos formar com eles uma caixa de música que pode operar mecanicamente, quimicamente ou eletricamente, já que cada um dos sinos responde a qualquer tipo de estímulo com seu próprio tom característico. Mas o significado de uma caixa de música viva não consiste nisso, dado que ela seria um mero mecanismo (...), se fosse guiada elétrica ou quimicamente. Uma caixa de música feita por sinos vivos deve possuir a habilidade de tocar sua música não apenas com base em um dispositivo mecânico, mas também guiada por sua melodia (2010, p. 148).

Aliás, os sinos vivos não tocam sozinhos. Eles também produzem música em resposta à música de outros sinos vivos (p. 16o).

Deixando a metáfora musical, os organismos desenvolvem-se e evoluem a partir da inclusão, em seus Umwelten, de novos veículos (carrier) de significado (p. 140-1), objetos e sujeitos externos, os quais modificam sua percepção do mundo, seu comportamento e até sua morfologia. Na ontogenia, operam tanto os mecanismos físico-químicos responsáveis do desenvolvimento, quanto os veículos do significado. Como evidência 
de que os dois processos são distintos, Uexküll cita o experimento de Hans Spemann com transplante de células embrionárias (p. $15^{2-7}$ ). Enquanto o processo físico-químico do desenvolvimento determina cegamente certas características morfológicas, a "caixa de música celular", constituída pelo entorno semanticamente carregado da vida em qualquer nível, determina aquelas características do organismo que o tornam propriamente um sujeito, dotado de um Umwelt e capaz de interpretar os significados para ele relevantes. Na filogenia (p. 170), um processo que Uexküll considera muito menos importante para entender a constituição atual dos seres vivos, age um mecanismo análogo ao que caracteriza a ontogenia. A natureza, contrariamente ao que sustentam os evolucionistas - Uexküll cita, como representante destes, Spencer (p. 185) -, não procura um melhoramento das espécies, uma seleção dos indivíduos mais aptos, mas uma harmonia entre eles e a estabilidade do ecossistema.

A natureza é uma orquestra, na qual cada instrumento encontra seu lugar exato, e toca sua melodia acompanhado pelos outros instrumentos, que constituem seu contraponto (p. 185-7). Os processos físico-químicos, mecânicos, são subordinados a uma regra superior, aquela que Uexküll chama de "regra de significado", que conecta a totalidade do orgânico de acordo com as capacidades de percepção e de efeito de cada indivíduo (p. 168-ұ3). A música da natureza é aquela que liga o carrapato com o mamífero, o morcego com a mariposa, com a qual compartilha uma mesma frequência de sons (p. 177-8), a árvore de carvalho com a chuva e o sol (p. 173), e todos os seres que ocupam algum nicho no próprio carvalho. É a transmissão de significado entre seres tão diferentes entre si que, do ponto de vista de Uexküll, constitui o verdadeiro mistério da natureza. "Se a flornão fosse abelhada, e se a abelh a não fosse florada, a consonância nunca poderia funcionar" (p. 190, grifo no original). A inspiração goethiana é aqui manifesta: "se o olho não fosse ensolarado, não poderia avistar o sol" (Goethe apud Uexküll, 2010 , p. 190). Deve existir, além dos ciclos funcionais particulares, um motor universal que coordene as caixas de música vivas, para que o efeito final seja uma harmonia e não uma cacofonia. Nas páginas finais de $A$ theory of meaning, o objetivo do biólogo é claramente caracterizado como a descoberta das "tecnologias da natureza" (p. 192-4, 202-3), entendidas como o conjunto das inúmeras conexões entre os ciclos vitais e de significado. Somente Lamarck, segundo Uexküll, dedicou-se seriamente, até a atualidade, a essa tarefa (p. 194).

Em definitivo, Uexküll abraça sem hesitações uma imagem do mundo orgânico intrinsecamente teleológica, na qual os significados que caracterizam o Umwelt do indivíduo não representam um aspecto secundário e derivado da evolução biológica mas, ao contrário, o verdadeiro elemento característico da vida. A citação de Machado, com a qual abri esta resenha, é ilustrativa. Para Uexküll, a imediatez do mundo vivido, harmonicamente afinado com os objetos da percepção e da ação, é a medida de todas 
as coisas. O mundo é principalmente Umwelt, e só de maneira derivada mundo físico. O sujeito lança luz sobre a realidade, tornando vivas as coisas mortas, enchendo de significado o que, de outro modo, seria mudo.

Ao leitor contemporâneo, Uexküll poderia parecer um autor anacrônico, devido ao forte elemento metafísico e pré-darwiniano presente em sua obra. Mas essa leitura seria superficial e apressada, já que negligenciaria a grande originalidade e fecundidade científica de alguns temas recorrentes nos textos aqui tratados. Em primeiro lugar, é importante salientar a horizontalidade da visão uexkülliana do mundo orgânico. Não existe, no universo do autor, uma jerarquia de formas de vida, como em boa parte do evolucionismo - biológico e filosófico - do século XIX, e ainda do século xx (cf. Lorenz, 1974; Caponi, 2012; Baravalle, neste número). Todo animal tem suas especificidades, nenhum Umwelt é "melhor" que outro. Com certeza, alguns são mais articulados e abrangentes, mas não faz sentido comparar os mundos vividos. Em minha opinião, essa horizontalidade é mais compatível com o darwinismo que a imagem progressivista e antropocêntrica que, ainda hoje, é muito difundida.

Em segundo lugar, a noção uexkülliana de "regra de significado" não tem o propósito de escamotear a recusa da noção de causalidade dos behavioristas, o que faria dela uma complicação supérflua para justificar a irredutibilidade de processos não mecanicistas. Ela é antecipadora, em certa medida, da noção de "informação" que, a partir de Shannon (1948), adquirirá cada vez mais relevância em biologia e que, hoje em dia, joga um papel fundamental na explicação da relação entre os organismos e o ambiente (cf. Godfrey-Smith \& Sterelny, 2008). Em particular, ela representa um dos conceitos fundamentais, juntamente com as noções de ciclo vital e de Umwelt, da biosemiótica (Hoffmeyer, 2008; Emmeche \& Kull, 2011), uma área disciplinar que se encontra hoje em rápida expansão. Entendida como a confluência da semiótica peirciana com a teoria uexkülliana, a biosemiótica "já não é uma escola de pensamento marginal (...) mas uma nova biologia a ponto de encontrar seu próprio fundamento teórico" (Emmeche \& Kull, 2011, p. 4).

Finalmente, a defesa que a obra de von Uexküll oferece do papel da filosofia em biologia é, por si só, louvável. Contrariamente à tendência reducionista dos fisiólogos seus contemporâneos, e longe da epistemologia fisicalista do empirismo lógico, Uexküll marca uma continuidade com o pensamento romântico oitocentista e reivindica o dever intelectual à busca de perguntas mais profundas que as que a ciência atual pode responder, principalmente graças à indagação metafísica. A música esconde estruturas desconhecidas para quem não sabe escutá-la com a devida atenção; as dinâmicas da vida têm a mesma tendência a ocultar-se, até em um carrapato. Só o espírito livre das imposições dos modelos aceitos pode desvendá-las. 
Lotenzo Baravalle

Centro de Giências Naturais e Humanas, Universidade Federal do ABC, Brasil. lorenzo_baravalle@yahoo.it

\section{Waltz for ticks}

\section{REFERÊNGIAS BIBLIOGRÁFICAS}

Agamben, G. Lo abierto. Buenos Aires: Hidalgo, 2006.

Baravalle, L. Animalidade transcendental: o problema da naturalização do a priori em Konrad Lorenz. Scientiae Studia, 12, 2, p. 285-305.

Caponi, G. Tipología y filogenía de lo humano. Ludus Vitalis, 20, 37, p. 175-91, 2012.

Cassirer, E. El problema del conocimiento. Ciudad de México: Fondo de Cultura Económica, 1979 · 4 v.

Godfrey-Smith, P. \& Sterelny, K. Biological information. The Stanford encyclopedia of philosophy. 2008. Disponível em: <http://plato.stanford.edu/archives/fall20o8/entries/information-biological/>. Acesso em: $3 \circ$ jul. 2014.

Еммесhe, C. \& KulL, K. Towards a semiotic biology. Life is the action of signs. London: Imperial College Press, 2011.

HeIdegger, M. The fundamental concepts of metaphysics: world, finitude, solitude. Bloomington, Indiana: Indiana University Press, 1995.

Hoffmeyer, J. Biosemiotics: an examination into the signs oflife and the life of signs. Scranton, Pennsylvania: University of Scranton Press, 2008.

Jablonka, E. \& Lamb, M. J. Evolução em quatro dimensões. DNA, comportamento e a história da vida. São Paulo: Companhia das Letras, 2005 .

Lorenz, K. L'altra faccia dello specchio. Milano: Adelphi, 1974.

O'NeIL, J. Translator's introduction. In: UEXKüLL, J. von. A foray into the worlds of animals and humans / A theory of meaning. Minneapolis/London: University of Minnesota Press, 2010. p. 35-8.

Shannon, C. A mathematical theory of communication. Bell Systems Technical Journal, 27, p. 279-423, $623-56,1948$.

UeXKüLL, J. von. A forayinto the worlds of animals and humans/A theory of meaning. Minneapolis/London: University of Minnesota Press, 2010.

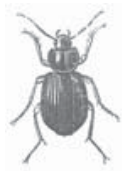

